\title{
An Ecological Economic Interpretation of Agro- Ecological Capital Operation and Coordination Among Targeted Poverty Alleviation Regions
}

\author{
Tian $\operatorname{Tian}^{1, *}$
}

\author{
${ }^{1}$ Wuchang University of Technology, Wuhan, Hubei 430073, China \\ *Corresponding author. Email: 932060908@qq.com
}

\begin{abstract}
The concept of "ecology, green, poverty alleviation" has been increasingly influencing the agricultural development. Agro-ecological capital operation defines the role of agro-ecological environment in green development, and seeks to achieve the maximum economic and social benefits of agricultural production at the lowest ecological environmental cost, so as to reduce the poverty of farmers. Starting from the coordination between targeted poverty alleviation and regional ecological capital operation, this paper describes the pro-poor effect of ecological capital operation from three aspects of ecology, economy and society - reasonably operating the ecological capital, taking the development and operation of ecological resources as the priority among priorities in the region of poverty alleviation and increasing the supply of ecological products and the ecological capital stock in poor areas continuously, so as to maximize the long-term benefits of ecological capital. Both as ways of ecological protection and poverty alleviation, regional coordination of agro-ecological capital operation and targeted poverty alleviation interact with each other. Scientific operation of agro-ecological capital is an important approach to targeted poverty alleviation, which promotes targeted poverty alleviation with ecological protection from the aspects of regional talent cultivation, industrial transfer and park construction. Under the guidance of the concept of green development and protection of poverty alleviation, poor households can preserve and produce more agricultural capital and provide favorable conditions for sustainable agricultural operation and economic development in poverty alleviation regions, so as to get rid of poverty and become better off at an early date.
\end{abstract}

Keywords: agro-ecological capital operation, targeted poverty alleviation, regional coordination, pro-poor effect

\section{INTRODUCTION}

Agriculture is an ecological industry, and the production process of agriculture is a process in which people constantly transform the form of agricultural ecosystem to meet their own development needs. Since the agricultural ecosystems have good air, water and other ecological resources, farmers in poor areas actually play a dual role of protecting and improving the ecosystem. The agro-ecological capital operation clarifies the role of agro-ecological environment in the green development of agriculture, and seeks to achieve the maximum economic and social benefits of agricultural production at the lowest cost of ecological environment, so as to reduce farmers' poverty. The essence of targeted poverty alleviation policy is to use the power of the government to solve the poverty phenomenon in the process of social and economic development. The combination of agro-ecological capital operation and targeted poverty alleviation can change the original dependence on external forces to alleviate poverty. It emphasizes rational exploitation of agricultural natural resources, scientific operation of agro-ecological capital, and improvement of human capacity on the basis of resource utilization, so as to promote coordinated development of targeted poverty alleviation and agro-ecological capital operation.

The study on the benefit of agro-ecological capital in foreign countries began earlier. Terry L. Anderson (2000) used a large number of cases in his book "Enviro-Capitalists - Doing Good While Doing Well" to illustrate how to rely on the power of individual enterprises, communities and local governments to protect ecological resources through commercial means and create profits while devoting themselves to environmental protection Deng Yuanjian (2017) elaborated the three development modes of agro- 
ecological capital operation from the perspective of "pro-poor type" agro-ecological capital operation, namely, three development modes of low-carbon, green and circular agro-ecological capital operation, giving full play to the economic, social and ecological effects of agro-ecological capital operation. Zhang Wenming and Zhang Xiaode (2019) constructed a framework for capitalization of ecological resources - under certain conditions, some ecological resources can be converted into ecological assets for trading, and they proposed resource pricing and output value estimation to invest and operate ecological assets.

From the present situation of the research of ecological capital, most of scholars believe that since poor areas tend to have more superior natural resources, farmers in poor areas need to restrict the development of ecological resources and the ecological capital operation in order to protect ecological resources, and that reasonably operating agro-ecological capital is an important way in poor areas farmers out of poverty. Few studies have combined the operation of agroecological capital with targeted poverty alleviation to achieve the effect of pro-poor effect through the regional coordination mechanism. Therefore, from the perspective of pro-poor effect, this paper interprets the development mode of poverty alleviation from the perspective of ecological economics, and finds a road suitable for agricultural development and farmers' prosperity from the perspective of government's topdown poverty alleviation method and farmers' own development of ecological capital, so as to realize the important task of poverty alleviation.

\section{THE CONNOTATION OF AGRO- ECOLOGICAL CAPITAL OPERATION AND PRO- POOR EFFECT}

\section{A. The connotation of agro-ecological capital operation}

Agro-ecological capital operation refers to that the owners of agricultural resources take advantage of the unique regional characteristics of natural resources to incorporate agricultural natural resources into their assets, regard ecological assets as the investment activities of agricultural production and reproduction, and realize the value of ecological products or ecological services by trading in the ecological market, so as to meet the demand of the public for ecological products and reduce the damage to the ecological environment. The development process of agroecological capital operation is essentially the process of green development of rural economy and green transformation of social development. At present, the operation of agro-ecological capital is between the embryonic stage and the initial stage. People begin to pay attention to the green development mode and regard ecological protection and sustainable development as important development principles, which requires farmers to make scientific and reasonable use of agro-ecological resources spontaneously or by social groups. The main body of ecological capital operation includes the owners and operators of ecological capital, with its range not only limited to enterprises, but also covering the government, social organizations and the public. The natural advantages of ecological resources and their attributes of public goods make the property rights of ecological capital diversified. Therefore, in the early stage of agro-ecological capital operation, farmers need to rely on their own strength to overcome this complex task and promote the green development of agriculture. At the same time, it is necessary to establish and improve the relevant systems and mechanisms, improve the incentive and constraint policies of eco-capital operation, so as to promote regional coordination.

\section{B. The pro-poor effect of agro-ecological capital operation}

This paper mainly analyzes the pro-poor effect of agro-ecological capital from three aspects: ecology, economy and society. Firstly, the pro-poor effect of agro-ecological capital is to improve the agricultural production environment in the process of operating agro-ecological capital. From the perspective of longterm development, agricultural production and people's life is a continuous process, and such a way to develop resources can only lead to more poverty in farmers' lives. These gains are transformed into economic gains over time, and they can improve the fertility of the soil, enhance the production of agricultural products, and improve the standard of living of farmers. Therefore, $t$ is necessary to use the means of agro-ecological capital operation, combine with the resource advantages of poor areas, such as fresh air and good scenery and to properly develop tourism resources, so as to help farmers out of poverty. On the one hand, it not only promotes the sustainable development of agroecological resources, but also provides development space for the rehabilitation of agro-ecological environment. On the other hand, while providing subsidies to farmers, it is necessary to make the agricultural operators consciously protect the "green hills and clear waters" on which the sustainable development of agriculture depends.

Secondly, the pro-poor effect of agro-ecological capital operation is reflected in the economic pro-poor effect. The economic benefit of agro-ecological capital investment is to increase the output of ecological products by making use of the investment in ecological environment protection, and to reduce damage to the body and increase farmers' income due to an improved ecological environment. Generally speaking, the impact of investment in agro-ecological capital on the whole 
economy is manifested in two aspects. First, the scientific operation of agro-ecological capital increases the investment of agro-ecological capital, expands the production of enterprises and increases the social supply under the role of supply and demand mechanism, especially promotes the development of environmental protection, tourism and other industries, and promotes the growth of economic aggregate. Second, through continuous investment in agroecological capital to increase the stock of ecological capital, the preferential tax policies enjoyed by individuals in the process of agro-ecological investment can encourage enterprises to continuously improve science and technology, promote the improvement of people's quality of life and productivity level, so as to ultimately improve the efficiency of ecological capital

Finally, the pro-poor effect of agro-ecological capital operation is reflected in the social pro-poor effect. The social pro-poor effect refers to the positive influence brought by the operation of agro-ecological capital to the whole society, which involves the improvement of farmers' living conditions, the solution of farmers' employment problems and the protection of cultural sites. In addition, the operation of agroecological capital can increase the financial tilt of agriculture in poor areas, facilitate the implementation of targeted poverty alleviation work and narrow the gap between the rich and the poor.

\section{THE ECOLOGICAL ECONOMIC MECHANISM OF REGIONAL COORDINATION FROM THE PERSPECTIVE OF THE INTERNALIZATION OF THE PRO-POOR EFFECT}

The ecological economic mechanism in this paper is from the perspective of an internalized pro-poor effect of the agro-ecological capital operation, to study the interaction and the law of the interaction among the main bodies and components of the poor areas and their relationship of assistance and promote the organic connection between the components, so as to achieve the purpose of promoting the development of agroecological economy. The explanation is made mainly from the aspects of ecological cooperation mechanism, ecological compensation mechanism and ecological incentive mechanism.

\section{A. Agro-ecological cooperation mechanism for regional poverty alleviation}

China's poor areas are characterized by large regional span, complex internal conditions and exceptional poverty in contiguous areas, which requires regional cooperation in poverty alleviation and common development. So it is necessary to combine the poverty alleviation funds in the poor areas with the operation of agro-ecological capital and follow the laws of agricultural natural resources and economic and social development. Since the ecological cooperation mechanism is the overall operation of each link of the ecosystem, the diversity and complexity of agroecological capital property right subject should also be considered in the formulation of agricultural industry, agricultural system and policy. It is important to carry out omni-directional and multi-level exchanges and cooperation in agro-ecological tourism and production of agricultural products on the basis of maintaining agro-ecological capital and sustainable development of regional environment. The ecological cooperation mechanism of agro-ecological capital operation and targeted poverty alleviation is a new way to lift farmers out of poverty and make them rich. Efforts should be made to help the poor areas achieve sustainable ecological development and increase the stock of ecological capital, and realize the coordination mechanism of sharing resources, environment and strategies within contiguous poverty-stricken areas, so as to achieve the unity of economy, society and ecology and achieve common development within the regions.

\section{B. Agro-ecological compensation mechanism for regional poverty alleviation}

The agro-ecological compensation mechanism in the region of poverty alleviation refers to taking corresponding measures to restore and improve the agricultural ecosystem, internalizing the externality of some agricultural production activities, and adjusting the distribution principle of stakeholders that protect and destroy the ecological environment. It is an economic compensation behavior. Targeted poverty alleviation requires precise management of poverty alleviation work, and the mechanism of agro-ecological compensation involves three aspects: the government, the society and the market, mainly referring to the local government, farmers and enterprises in the areas of poverty alleviation and development. The establishment of agro-ecological compensation mechanism contributes to combining the development and utilization of agro-ecological capital with the reproduction of general commodities by means of economic incentives and social macro-management. The government's ecological compensation mechanism aims at the ecological security, coordinated development and social stability of the region, with state or the government at a higher level as the main body of compensation, the grassroots government and farmers in the poverty alleviation region as the object of compensation, and the agro-ecological environment as the object of compensation. In the process of targeted poverty alleviation, the government plays an important role in the agro-ecological compensation mechanism for farmers' development or protection of ecological resources, and compensates from financial subsidies, project preference and policy support. The market mechanism of ecological compensation is to improve 
the ecological economic activities by the market participants using economic means. The market plays a fundamental role in optimizing the allocation of resources. It can reward the performance or allocate the quota of agricultural environmental pollution control and realize the service function and value of agroecological resources. The social mechanism of agroecological economic compensation can play an effective role only by farmers' self-restraint and environmental protection consciousness, which is also the manifestation of precise management.

\section{Agro-ecological incentive mechanism for regional poverty alleviation}

Capital has the property of appreciation. As a special factor of production, and ecological products produced in the process of combining with other agricultural factors of production, agro-ecological capital can realize its value by being sold in the market. The operation of agro-ecological capital is a means to realize the value of ecological capital. And agroecological resources, as a scarce resource, requires the government in the process of precise poverty alleviation to follow the objective laws of economic and natural development, help newly-built enterprises or enterprises in difficulty to solve the shortage of funds caused by poverty, guide enterprises to invest in agro-ecological capital, innovate the production technology of agroecological products, improve the agricultural ecology resources use efficiency and develop the agricultural products that meet the market demand, so as to improve infrastructure in poor areas and promote the living standards of farmers. At the same time, in order to maximize the profit from the operation of agroecological capital, farmers in poverty alleviation areas should be guided to establish the concept of green development. In the process of developing and utilizing agricultural natural resources, sustainable development should be taken as an important principle, ecological protection should be adhered to, and ecological capital concept should be established to promote the development of regional economy. In this way, the material flow and energy flow of the agro-ecological economic system in targeted poverty alleviation areas will be affected, so as to achieve the purpose of improving and restructuring the common development of "agro-ecology - rural revitalization — social prosperity" in poverty alleviation areas.

\section{THE ECO-ECONOMIC STRATEGY FOR AGRICULTURAL ECO-CAPITAL OPERATION AND TARGETED POVERTY ALLEVIATION}

\section{A. The industrial transfer policy of regional poverty alleviation}

The key to solving poverty is to build enterprises in poor areas and promote industrial transfer. Industrial transfer must take into account the natural environment and social and economic conditions of poverty alleviation areas, and should not only be based on the current situation, but also play a long-term role of enterprises. As for the transferred industries undertaken by poverty alleviation areas, on the one hand, they should meet the requirements of agricultural ecology and green development, take advantage of regional resources as the basis, comprehensively consider the conditions of agricultural production technology and agricultural product market, and combine the development of agricultural parks with industrial transfer under the premise of attaching equal importance to resource development and protection, so as to help poor farmers form new ideas for industrial development. Second, it is necessary for them to construct the concept of regional agro-ecological capital, to define the main body of regional agroecological capital and the division of property rights, to develop agro-ecological resources to different degrees and reasonably develop related agricultural industries according to the differences in natural conditions in poor areas. Third, in the poor areas where industrial transfer is accepted, farmers should actively adapt to the development mode of enterprises, change the traditional backward operation mode, and accept the advanced culture of agricultural enterprises.

\section{B. Regional personnel training policies for poverty alleviation}

Human, material and financial resources are indispensable resources in the process of targeted poverty alleviation, and labor is the key component of targeted poverty alleviation. The backward educational facilities in the poverty alleviation areas and the relatively low educational level of the peasants are also constraints to the development of the rural economy. Therefore, in order to better carry out targeted poverty alleviation work and change the traditional mode of production in which farmers sacrifice natural resources to obtain economic benefits, it is necessary to strengthen the training of labor force. First, it is necessary to guide the farmers in the poverty alleviation region to rationally develop local resources, integrate the advantages of resources and improve the efficiency of ecological capital operation, so as to avoid falling into more poverty due to environmental degradation. Secondly, based on the characteristic industries in poor areas, the corresponding farmers should be given skill 
training and training subsidies according to the degree of poverty, and different training sites should be divided according to the training objects and training contents, so as to integrate funds and enable farmers to learn more skills. In this way, the employment skills of poor farmers will be improved, which will increase their incomes and help them to become new type of skilled farmers. Finally, poor farmers should be encouraged to enter township enterprises or go out for work, which can not only directly rely on external forces to force poor farmers to change their backward ideas, but also play a certain role in improving the agroecological environment in poor areas.

\section{The policy of joint construction of parks for regional poverty alleviation}

The policy of joint construction of parks refers to that with their own development pattern and strategic status of continuously improving, cities with better economic development have an obvious pulling effect on the economic development of the targeted poverty alleviation areas in the surrounding areas, and expand the scope of their influence. The agro-ecological resources in poverty alleviation areas are extremely fragile and yet very abundant. According to the traditional advantages of agricultural development in poverty alleviation areas, based on the endowment of agricultural resources, relying on agricultural parks in surrounding areas, and using the concept of ecological capital operation, the land, capital and other means of production of poor farmers can be centralized and integrated. In the form of investment of agro-ecological capital, family farms or agricultural cooperatives should be set up to form the poverty alleviation model of "company + agricultural park + poor household" and obtain long-term benefits. This kind of development policy of joint construction of parks can better identify the poor objects with poor economic conditions and weak labor capacity, and can take land or rent as the agro-ecological capital to invest in the parks, which means carrying out land-based poverty alleviation or poverty alleviation by means of becoming a shareholder according to the development of the parks. The development of agricultural parks also provides employment opportunities for farmers, and the effects of absorbing poor farmers and promoting their poverty alleviation can be timely evaluated, which will help the government to timely adjust poverty alleviation policies, establish an exit mechanism for poverty alleviation and achieve the dual goals of green agricultural development and targeted poverty alleviation.

\section{CONClusion}

There is an inherent link between the operation of agro-ecological capital and targeted poverty alleviation, which provides the basic conditions for the coordinated development between the two sides. The goal of targeted poverty alleviation is to help farmers in poor areas increase their income while meeting their basic living needs. The purpose of agro-ecological capital operation is to provide a good ecological foundation for sustainable development. The essential purpose is to use agro-ecological environmental resources as a kind of capital to invest in production and operation activities to save resources and reduce the negative impact of economic production on agricultural production environment. It promotes the technology of ecological productization with high economic benefits, and continuously explores the mode to promote the realization of the value of agro-ecological products, contributing to promoting the coordinated and sustainable development of "eco-economy-society". Therefore, the utilization and development of agroecological resources and the environment has become the key factor for the poor people in poor areas to get rid of poverty, which objectively requires the coordinated promotion of ecological capital operation and targeted poverty alleviation.

\section{References}

[1] Terry L. Anderson, Donald R. Leal. Enviro-Capitalists Doing Good While Doing Well [M]. Tqinghua University Press, 2000.

[2] Huang Li, Yan Lidong. Study on the Components of Ecological Capital Operation: from the Perspective of Functionalism [J]. Henan Social Sciences, 2013 (3). (in Chinese)

[3] Yan Lidong, Liu Jialin, Chen Guangju. Study on the Value of Ecological Capital Operation[J]. China Population,Resources and Environment, 2011 (1). (in Chinese)

[4] Gao Shiji, Wang Haiqin, Li Weiming. Observation on the Course and Orientation of Institutional Reform of Ecological Civilization in the Past 40 years of Reform and Opening Up [J]. Reform. 2018(08). (in Chinese)

[5] Cai Dianxiong. Ecosystem Services for Poverty Alleviation [M]. Science Press, 2011. (in Chinese)

[6] Wang Yanlong, Sun Qiming, Wei Jieyu. The Application of Ecological Capital Operation Theory in Western China [J]. Resource Development \& Market, 2011. (12). (in Chinese)

[7] $\mathrm{Hu}$ Naiwu, Li Peijie. The Transformation of Ecological Advantages to Economic Advantages [J]. China Finance. 2017 (08). (in Chinese)

[8] Li Xuejiao, He Aiping. Constraints on Green Development and Their Paths [J]. Reform. 2016(06). (in Chinese)

[9] Chen Lin. Review of Domestic Research Progress on Ecological Capital [J]. Times Finance, 2018(20): 42+44. (in Chinese)

[10] Zhang Wenming, Zhang Xiaode. The Capitalization of Ecological Resources: An Explanatory Framework [J]. Reform, 2019(01): 122-131. (in Chinese) 